matter of just not practice the damage, we need to do well; you must use the scientific foundations and implementing existing legislation in favour of the collective rather than the personal interests of the subject; on the principle of justice, it must use the law in the constitution of an ordered society with a view to holding a social life happy, giving each one what is his or each of which is for him or that is his due.

\section{PRIORITISATION EXERCISE FOR THE PROBE PROJECT (HAZARDOUS CHEMICAL PRODUCTS REGISTER FOR OCCUPATIONAL USE IN BELGIUM)}

\begin{abstract}
${ }^{1}$ Steven Ronsmans*, ${ }^{2}$ Sara Pauwels, ${ }^{3,4}$ Anne-Marie Temmerman, ${ }^{1,5}$ Antoon De Schryver, ${ }^{6,7}$ Dorina Rusu, ${ }^{3}$ Lutgart Braeckman, ${ }^{2,5}$ Lode Godderis. ' University of Antwerp, Departement of Epidemiology and Social Medicine, Antwerpen, Belgium; ${ }^{2} \mathrm{KU}$ Leuven - University of Leuven, Department of Public Health and Primary Care, Environment and Health, Leuven, Belgium; ${ }^{3}$ Ghent University, Department of Public Health, Gent, Belgium; ${ }^{4}$ OCMW Brugge Public Social Welfare Centre Bruges, Service for Prevention and Protection at Work, Brugge, Belgium; ${ }^{5}$ IDEWE, External Service for Prevention and Protection at Work, Heverlee, Belgium; ${ }^{6}$ University of Liège, Faculty of Medicine, Liège, Belgium; ' SPMT-ARISTA, External Service for Prevention and Protection at Work, Brussels, Belgium
\end{abstract}

\subsection{6/oemed-2018-ICOHabstracts. 1101}

Introduction The PROBE (Hazardous chemical Products Register for Occupational use in Belgium) study consists of a systematic collection of occupational chemical exposure data of Belgian workers. To test the feasibility of our approach a pilot study will be conducted using a concise list of priority chemicals.

Methods A targeted method was used to construct a priority list of chemicals relevant for the Belgian workplace context. In a first step, five recent European reports on prioritisation exercises of workplace chemicals were reviewed. All reports constructed a priority list based on different combinations of relevant sources: hazard information, health effects, exposure data, volume used and limit value databases. The appearance of a chemical in at least 2 prioritisation reports was used as a selection criterion for our list. In this way, we used the accumulated expertise of these reports to extract a preliminary list of 16 chemicals.

In a second step relevancy for the Belgian workplace context was evaluated using a number of sources: data on occupational exposure collected by Occupational Health Services, available biomonitoring and workplace measurements, REACH registrations for Belgium, data from the labour inspection and data on recognised occupational diseases by the Belgian Fund for Occupational Diseases. Fourteen out of the 16 chemicals listed in the preliminary list appeared to be relevant for the Belgian context.

Result A priority list of 14 chemicals was constructed for the pilot study of PROBE: crystalline silica, diesel exhaust and PAHs, wood dust, formaldehyde, asbestos, isocyanates, benzene, organic solvents, lead, beryllium, powder coating, refractory ceramic fibres, welding fumes and cadmium.

Discussion This stepwise approach made it feasible to select a concise number of priority chemicals. In the coming months, exposure data on these chemicals will be collected in a sentinel study and an evaluation of the appropriateness of the selection will be performed.
732

APPLICATION OF POSITRON EMISSION TOMOGRAPHY BASED IMAGING IN THE MANAGEMENT OF PNEUMOCONIOSIS CASES: A LITERATURE REVIEW

${ }^{1}$ Abdulsamet Sandal*, 'Seval Müzeyyen Ecin, ${ }^{1}$ Adem Koyuncu, ${ }^{2}$ Ali Naci Yildiz. 'Hacettepe University, Faculty of Medicine, Department of Internal Medicine, Unit of Occupational Medicine, Ankara, Turkey; ${ }^{2}$ Hacettepe University, Faculty of Medicine, Department of Public Health, Ankara, Turkey

\subsection{6/oemed-2018-ICOHabstracts. 1102}

Introduction We aimed to evaluate case reports and research articles subjected the usage of positron emission tomography (PET) or PET combined with computed tomography (PET-CT) in pneumoconiosis patients.

Methods 'Pubmed' and 'Web of Science' databases were queried with keywords of 'pneumoconiosis and PET' and 47 records were reached. Inclusion criteria were language (English or Turkish), publication date before 15th April, 2017, article type (case reports, case series and research articles), subject as usage of PET or PET-CT in management of pneumoconiosis cases. Articles not meeting at least one criteria were excluded. After those criteria applied 6 case reports, 5 case series, and one research article were evaluated.

Result Article contents were categorised according to purpose of PET or PET-CT (investigation of malignancy or differential diagnosis of benign pathology) and contribution of PET or PET-CT in the management (compatible with final diagnosis, compatible with final staging, or false positive). For 6 case reports, purpose was malignancy investigation in 5 (3 with false positive results and 2 with results supporting final diagnosis), and differential diagnosis of benign pathology in one report (with results supporting final diagnosis). Purpose was malignancy investigation in all case series (3 reports with false positive results, one report with results compatible with final diagnosis, and one report with results compatible with final staging) with number of cases 3-42. The research article aimed to investigate pulmonary nodules with both $11 \mathrm{C}$ methionine-(MET)-PET and fluorine-18-(F-18)-fluorodeoxyglucose(FDG)-PET in 26 patients and revealed more increased uptake values in malignant nodules compared to pneumoconiotic nodules.

Discussion Despite results revealing benefits of PET or PETCT in management of pneumoconiosis cases, their application should be carefully evaluated due to false positive results. Future researches in detection of cut-off uptake values between benign pneumoconiotic nodules and malignant lesions may be useful.

\section{EVALUATION OF PNEUMOCONIOSIS IN TURKEY'S ANNUAL STATISTICS OF OCCUPATIONAL DISEASES BETWEEN 2006 AND 2015}

${ }^{1}$ Adem Koyuncu*, 'Abdulsamet Sandal, ${ }^{1}$ Seval Müzeyyen Ecin, ${ }^{2}$ Ali Naci Yildiz. ${ }^{1}$ Hacettepe University, Faculty of Medicine, Department of Internal Medicine, Unit of Occupational Medicine, Ankara, Turkey; ${ }^{2}$ Hacettepe University, Faculty of Medicine, Department of Public Health, Ankara, Turkey

10.1136/oemed-2018-ICOHabstracts. 1103

Introduction Republic of Turkey Social Security Institution (SSI) is the institution responsible for statistics of occupational 